\title{
The Relationship Between Coach and Player Training Load Perceptions in Professional Soccer
}

Perceptual and Motor Skills 2017, Vol. 124(I) 264-276

(C) The Author(s) 2016

Reprints and permissions: sagepub.com/journalsPermissions.nav DOI: $10.1177 / 003|5| 2516678727$ journals.sagepub.com/home/pms

@SAGE

\section{Paulo Eduardo Redkva', Sergio Gregorio da Silva², Mauro Ricetti Paes ${ }^{3}$, and Julio Wilson Dos-Santos ${ }^{1,4}$}

\begin{abstract}
The training load imposed and perceived by coaches and soccer players, respectively, was compared for three weeks of the basic preparatory period of a professional soccer team through session ratings of perceived exertion (S-RPE). Participants were 24 professional Brazilian soccer players (all males, age: $24.1 \pm 3.4$ years) and their coaches. Athletes responded to the scale of perceived exertion (scores from 0 tol0) after the training, while the coaches completed the scale prior to the training session, based on prior planning. The t-test for independent samples was used to compare SRPE responses, and the Pearson correlation test was used to examine possible correlations between the parameters analyzed. There were no statistical differences between perceptions of prescribed (coaches) and experienced (players) S-RPE, and moderate correlations were found between these parameters $(r=.60 ; p=.003)$. No statistically significant group differences were found in the perceived exertion during any of three types of training: physical, technical, or tactical. The results suggest that the S-RPE prescribed during the preseason period (by coaches) was not different from that perceived by professional soccer players.
\end{abstract}

\footnotetext{
'Post-Graduate Program in Sciences Motricity, UNESP - Univ Estadual Paulista, Rio Claro, Brazil

${ }^{2}$ Department of Physical Education, UFPR - Federal University of Paraná, Curitiba, Brazil

${ }^{3}$ Post-Graduate Program in Physiology, Federal University of Paraná, Curitiba, Brazil

${ }^{4}$ Department of Physical Education, UNESP_Univ Estadual Paulista, Bauru, Brazil
}

\section{Corresponding Author:}

Paulo Eduardo Redkva, Post-Graduate Program in Sciences Motricity, UNESP - Univ Estadual Paulista, Av. Eng. Luiz Edmundo Carrijo Coube I4-0I, Vargem Limpa., Bauru, São Paulo I7033-360, Brazil. Email: pauloredkva@gmail.com 


\section{Keywords}

session ratings of perceived exertion, training load, professional soccer

\section{Introduction}

Effective control of training loads requires coaches to have a good understanding of how athletes perceive the executed load, adequate rest, and any physiological adaptations resulting from successive training sessions (Buchheit et al., 2013; Impellizzeri, Rampinini, Coutts, Sassi, \& Marcora, 2004). Generally, prescription and monitoring of training loads are drawn up by coaches from their own perceptions of the external load (Coutts, Gomes, Viveiros, \& Aoki, 2010), in which parameters are used such as total training time, number of performed actions, and duration of the intervals and recovery periods during the session (Moreira, Freitas, Nakamura, \& Aoki, 2010).

Soccer is a sport characterized by intermittent actions where players develop high-intensity efforts (short duration) over different distances followed by periods of recovery at light intensities (Mohr, Krustrup, \& Bangsbo, 2003). Based on the sport's features, the need is evident for correct control of the training load to improve soccer players' performance. Thus, success in prescribing training programs for these athletes should be closely linked to monitoring and correctly quantifying the proposed training load (Impellizzeri, Rampinini, \& Marcora, 2005; Scott, Black, Quinn, \& Coutts, 2013).

As adaptations to training are associated with physiological stress imposed on athletes (Viru \& Viru, 2000), the planned sessions should take into account the desired internal load (physiological and perceptual response) for each training session (Andrade Nogueira et al., 2014). It is worth noting that several studies have investigated the differences between loads planned by coaches and the burden perceived by athletes from different sports (Borin, de Godoy Dias, dos Santos Leite, Padovani, \& Padovani, 2010; Foster, Florhaug, et al., 2001; Landis $\&$ Koch, 1977). Session rating of perceived exertion (S-RPE) has been used to demonstrate these inconsistencies between the training programs designed by coaches and the perceived exertion experienced by athletes (Foster, Heimann, Esten, Brice, \& Porcari, 2001).

Training load perception differences between coaches and players might provide a plausible explanation for the incidence of overtraining syndrome in elite athletes (Foster, 1998), since the mismatch between perceptions can have negative consequences on the efficiency of the proposed periodization (Foster, Florhaug, et al., 2001). Understanding these differences could corroborate the success or otherwise of the planned training. Recently, Brink, Frencken, Jordet, and Lemmink (2014) investigated the relationship between S-RPE throughout the competitive season of soccer players who were under 17 and under 19 years 
of age. The authors found that young soccer players considered the training harder than intended by the coach $(p<.001)$, which could promote unsatisfactory training adaptations (Brink et al., 2014).

In soccer, the preseason phase for a competitive season is normally conduced for only a few weeks and often includes a higher frequency of training sessions (Tessitore, Meeusen, Cortis, \& Capranica, 2007). However, to our knowledge, to date, information on the association between the external load (imposed by the coach) and internal load (perceived by the players) in professional soccer has not been established using only S-RPE to monitor the training load. Consequently, the aim of this study was to compare the perception of the external load of training sessions between coaches and players during three weeks of the basic preparatory period of a professional soccer team, through the S-RPE method. We hypothesized, based on studies involving individual and team sports (Andrade Nogueira et al., 2014; Brink et al., 2014; Coutts et al., 2010; Viveiros, Costa, Moreira, Nakamura, \& Aoki, 2011; Wallace, Slattery, \& Coutts, 2009), that the perceived S-RPE would be higher for coaches than players.

\section{Methods}

\section{Participants}

Twenty-four professional male soccer players (age: $24.1 \pm 3.4$ years; body mass: $78.3 \pm 9.2 \mathrm{~kg}$; height: $178.6 \pm 6.1 \mathrm{~cm}$; percentage of fat: $13.2 \pm 2.1 \%)$ and their coaches participated voluntarily in this study. All players were members of a team participating in the first division of the Paranaense Soccer Championship and participated in the national tournament (Brazil Cup) in 2014. The players trained for 5 or 6 days a week with one or two sessions per day, for about 2 to 4 hours a day. All players had previously undergone medical evaluation and were released for physical training. Technical staff: (a) Technical (Coach): 45 years, a professional soccer player between 1989 and 2006 and a professional soccer technician since 2008, working in elite teams of Brazilian soccer; (b) Physical trainer (Fitness coach): 45 years, degree in Physical Education with a postgraduate degree in sports training and exercise physiology. He worked as a physical trainer based in two elite category Brazilian soccer clubs between 1994 and 1998, between 1998 and 2001 as a trainer in Asian soccer teams (South Korea and China), and from 2001 until now as a trainer of professional soccer teams in Brazil. Data collection was performed during the 2014 preseason. The volunteers signed a consent form after being informed of the possible risks and benefits of the study. All procedures were previously approved by the Ethics Committee and were conducted according to the Declaration of Helsinki (1975, revised 1983). 


\section{Procedures}

Prior to each training session, the members of the technical committee responsible for the training session, technical or fitness coach, rated the RPE in accordance with "the main objective" determined by the technical coach for the training session (without interference from the researchers) and classified on a scale of 0 (resting) to 10 (maximum stress; Foster, Heimann, et al., 2001). For all players, as well as the duration (min) of the training session, all activities to be performed in the session, from the beginning of warm-up until the end of the training session, were also noted. After each training session, players assessed the training itself using the same scale, 0 to 10 (Foster, Florhaug, et al., 2001), through the following question: "How was your workout?" RPE is affected by a combination of external and internal factors (Lovell, Sirotic, Impellizzeri, \& Coutts, 2013; Scott, Lockie, Knight, Clark, \& Jonge, 2013; Scott, Black, et al., 2013), and therefore, the players were asked to rate their perceived exertion after about 30 minutes (Herman, Foster, Maher, Mikat, \& Porcari, 2006; Nakamura, Moreira, \& Aoki, 2010) to prevent the possibility that the exercises at the end of the training session were decisive in their answers (Foster, Florhaug, et al., 2001; Impellizzeri et al., 2004; McGuigan et al., 2008). Previously, both coaches (technical or fitness) and players were given verbal instructions about the necessary procedures (anchor) for accurate understanding of the use of the RPE scale.

\section{Training Sessions}

The training sessions evaluated comprised the first three weeks of preseason (Table 1), which was composed of five weeks. The fourth week of the preseason was aimed at physical assessments and training load was purposely reduced (tapered). In fifth week, there were two friendly matches with a consequent

Table I. Preseason Weekly Training Schedule.

\begin{tabular}{|c|c|c|c|c|c|c|c|}
\hline \multirow[t]{2}{*}{ Week I } & Day & $\begin{array}{l}\text { Mon } \\
10 / 28\end{array}$ & $\begin{array}{l}\text { Tue } \\
10 / 29\end{array}$ & $\begin{array}{l}\text { Wed } \\
10 / 30\end{array}$ & $\begin{array}{l}\text { Thu } \\
\text { |0/3I }\end{array}$ & $\begin{array}{l}\text { Fri } \\
\mathrm{I} \mid / 0 \mathrm{I}\end{array}$ & $\begin{array}{l}\text { Sat } \\
\text { II/02 }\end{array}$ \\
\hline & $\begin{array}{c}\text { Number of } \\
\text { sessions }\end{array}$ & - & 2 & 2 & I & I & I \\
\hline \multirow[t]{2}{*}{ Week 2} & Day & $\begin{array}{l}\text { Mon } \\
\text { I I/04 }\end{array}$ & $\begin{array}{l}\text { Tue } \\
\text { I I/05 }\end{array}$ & $\begin{array}{l}\text { Wed } \\
\text { I I/06 }\end{array}$ & $\begin{array}{l}\text { Thu } \\
\text { I I/07 }\end{array}$ & $\begin{array}{l}\text { Fri } \\
\text { I I/08 }\end{array}$ & $\begin{array}{l}\text { Sat } \\
11 / 09\end{array}$ \\
\hline & $\begin{array}{c}\text { Number of } \\
\text { sessions }\end{array}$ & 2 & 1 & I & 2 & I & 1 \\
\hline \multirow[t]{2}{*}{ Week 3} & Day & $\begin{array}{l}\text { Mon } \\
|I /| \mid\end{array}$ & $\begin{array}{l}\text { Tue } \\
11 / 12\end{array}$ & $\begin{array}{l}\text { Wed } \\
11 / 13\end{array}$ & $\begin{array}{l}\text { Thu } \\
\text { II//4 }\end{array}$ & $\begin{array}{l}\text { Fri } \\
\text { II//5 }\end{array}$ & $\begin{array}{l}\text { Sat } \\
11 / 16\end{array}$ \\
\hline & $\begin{array}{c}\text { Number of } \\
\text { sessions }\end{array}$ & 2 & I & I & I & I & I \\
\hline
\end{tabular}


reduction in load (volume and intensity) of training on the day before and succeeding each game. Therefore, only the sessions of the first three weeks of training were analyzed. In soccer, the preseason is normally conducted for only a few weeks and often includes a higher frequency of training sessions (Tessitore et al., 2007).

The training sessions were divided according to the main objective determined by the coaching staff for the training session (without interference from the researchers), divided into physical training, technical training, and tactical training. Of the total training hours (1,465 minutes) performed in the period, $32 \%$ (470 $\mathrm{min}$ ) was allocated to physical training, $20 \%(290 \mathrm{~min})$ to technical training, and $48 \%(705 \mathrm{~min})$ to tactical training. Table 2 describes the activities in the different training sessions.

\section{Session Rating of Perceived Exertion}

Calculation of the internal training load from the session RPE method (S-RPE) was determined by the RPE score of the product (scores from 0 to10) of the total session time (in minutes; Foster, Florhaug, et al., 2001; Foster, Heimann, et al., 2001). The session total time included all the activities, such as warm-up, main activity, return to calm, and intervals between activities or efforts for each session. S-RPE is expressed in arbitrary units (Foster, Florhaug, et al., 2001; Foster, Heimann, et al., 2001; Nakamura et al., 2010).

\section{Statistical Analysis}

Data are presented as means \pm one standard deviation $(S D)$. Initially, the Shapiro-Wilk test was used to verify the normality of the data. After confirmation of data normality, we used the t-test for unpaired samples for the variables

Table 2. Activities in the Different Training Sessions.

\begin{tabular}{lll}
\hline Physical training & \multicolumn{1}{c}{ Technical training } & Tactical training \\
\hline$\sim 15^{\prime}$ warm-up. & $\sim 15^{\prime}$ warm up. & $\sim 15^{\prime}$ warm up. \\
$\sim 20-40^{\prime}$ work principal & $\sim 30-60^{\prime}$ work principal & $\sim 30-60^{\prime}$ work principal \\
Content: & Content: & Content: \\
Sprint training; plyometric & Exercises with the ball & Small side Games, \\
and strength training & (pass, dribble, heading & collective, specific \\
session; resistance training. & accuracy, shot at goal), & work to develop \\
& body control and agility & standard of play \\
& exercises with the ball. & and tactical systems. \\
$\sim 5-10$ recovery & $\sim 5-10$ recovery & $\sim 5-10$ recovery \\
\hline
\end{tabular}




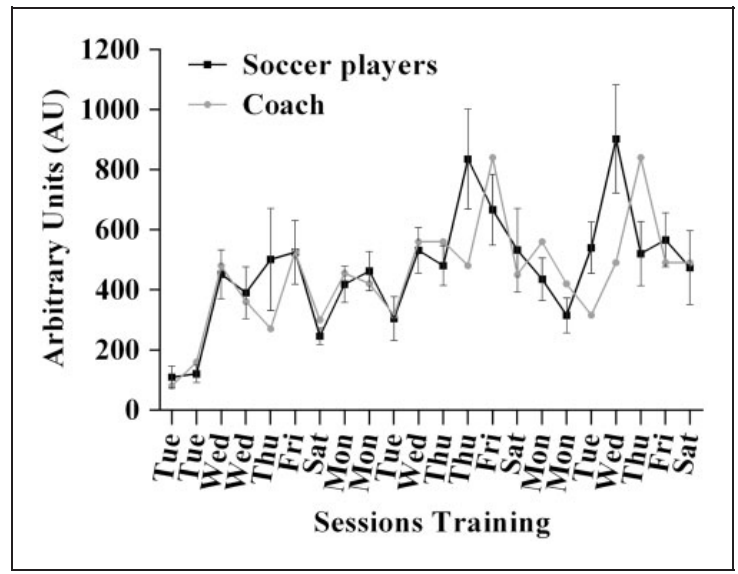

Figure I. Comparison of the S-RPE (AU) measured based on multiplication of session time (duration) versus RPE score. The RPE score adopted was prescribed by the coach or perceived by the soccer players. ${ }^{*} p<.05$.

obtained from S-RPE by players and coaches. The Pearson correlation test was used to assess the association between variables. The correlation coefficient was classified as weak to negligible ( 0 to 0.2$)$, weak $(0.2$ to 0.4$)$, moderate $(0.4$ to 0.7$)$, and strong (0.7 to 1.0; Rowntree, 1981). One-way ANOVA was used to verify the differences between the total workload for different applied training. If a significant $\mathrm{F}$ value was found, the Bonferroni post hoc test was used. The effect size (ES) was calculated according to Cohen (1988). The threshold values for Cohen's $d$ statistical power were considered as $>0.2$ (small), $>0.5$ (moderate), and $>0.8$ (large; Cohen, 1988). Statistical analyses were performed using the software SPSS 21.0. In all cases, a significance level of 5\% was considered.

\section{Results}

Data from 22 training sessions were collected during the basic preparatory period (preseason) from coaches and players. The average RPE score prescribed by the coaches was $6.7 \pm 1.78$ and the duration of the sessions (measured) was $67 \pm 21.5$ minutes. The average RPE perceived by the players was $6.8 \pm 1.43$. The S-RPE was calculated from the RPE score. No differences were found in the $\mathrm{S}-\mathrm{RPE}$ between players and coaches $(t=0.38 ; p=.70 ; \mathrm{ES}=0.05$; Figure 1$)$, and these two sets of ratings were moderately correlated $(r=.60 ; p=.003 ; \mathrm{ES}=0.05$; Figure 2).

Regarding the types of training proposed for the preseason period, differences were found in relation to time for tactical training in relation to physical 


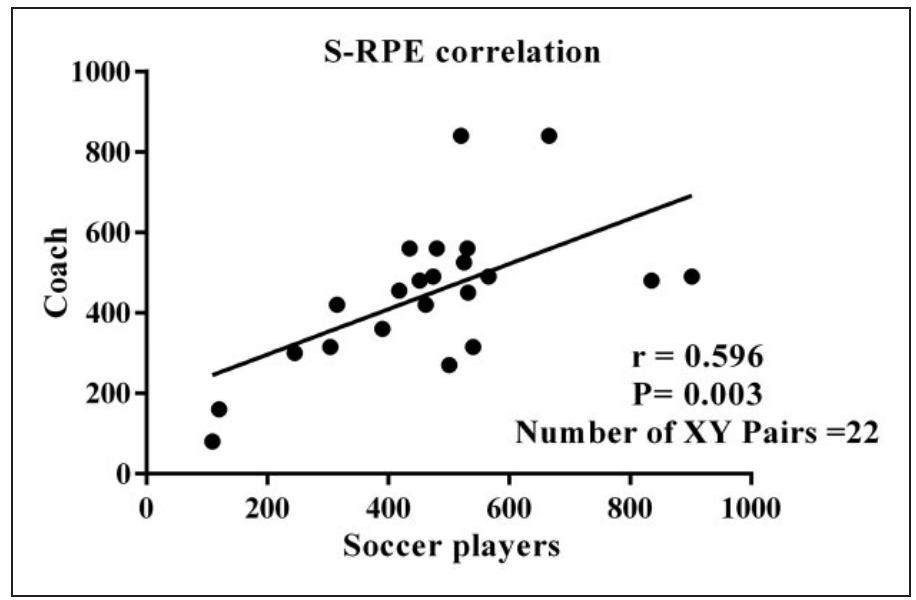

Figure 2. Relationship between the S-RPE prescribed by coaches and perceived by soccer players. $p=.003$.

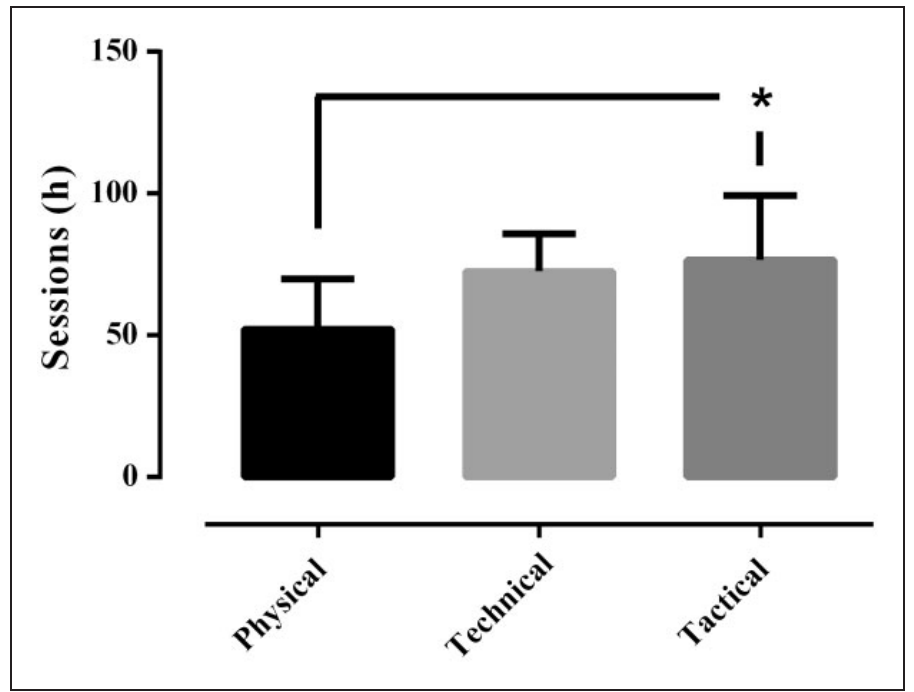

Figure 3. Comparison between the total load hours of the types of training applied during the 3 weeks of preseason. ${ }^{*} p<.05$.

training, $F(2,19)=4.785, p=.021 ; \mathrm{ES}=0.33$ (Figure 3). However, no statistical differences were found when comparing the S-RPE prescribed by coaches and perceived by soccer players $(p>.05)$ in the different proposed training types (Figure 4). 


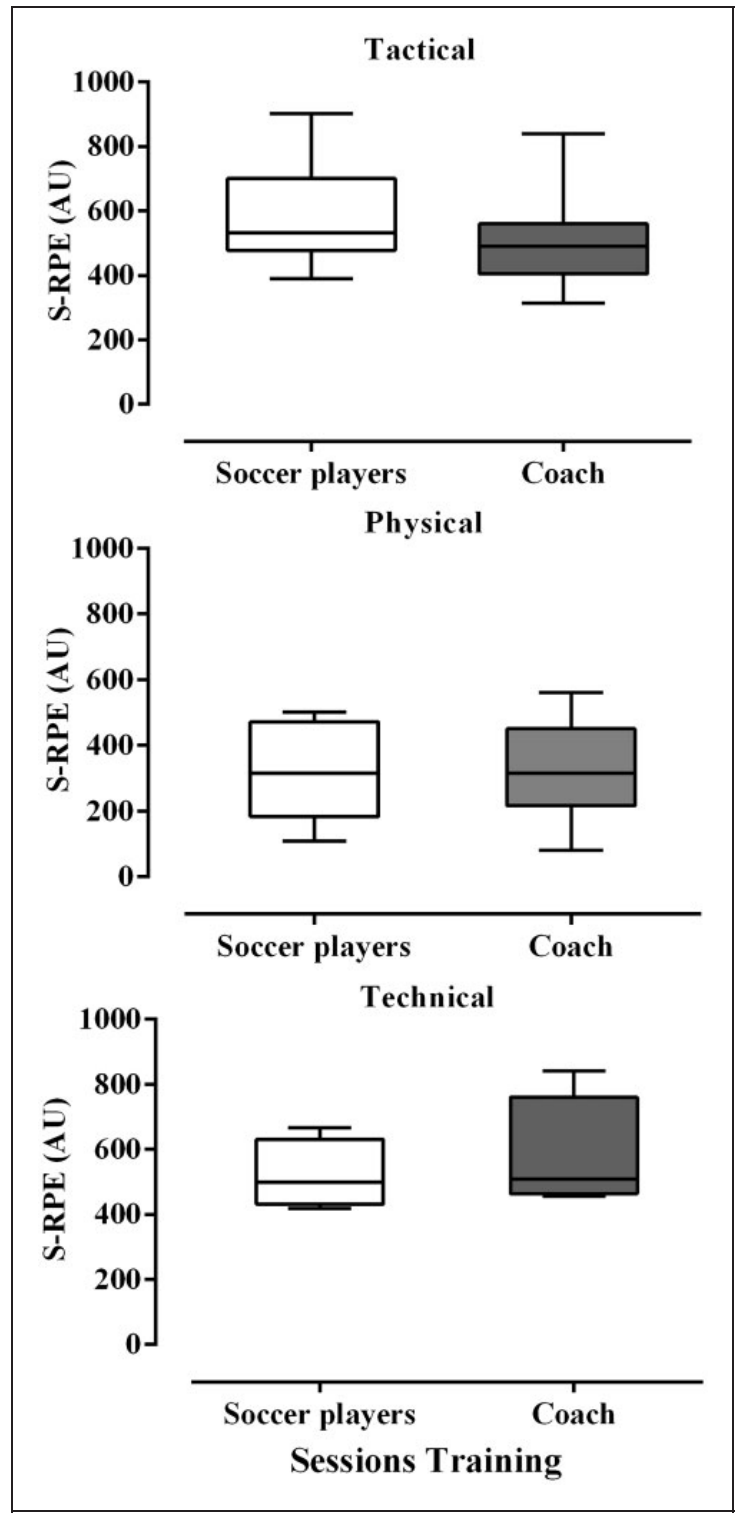

Figure 4. S-RPE comparisons of the different types of training prescribed during the 3 weeks of preseason. Data presented as means by number of sessions. ${ }^{*} p<.05$. 


\section{Discussion}

To our knowledge, this is the first study to examine the relationship between the S-RPE prescribed by the coach and perceived by soccer players in the professional soccer category. Based on these results, we refute our initial hypothesis as the S-RPE values were not statistically different (Figure 1) and presented moderate statistical correlation $(r=.60 ; p=.003)$ with a small ES. This demonstrates a good relationship between the prescribed training loads and those perceived by the athletes.

These results are in accordance with previous studies, which compared the relationship between training programs planned by coaches and those performed by runners (Foster, Heimann, et al., 2001) and swimmers (Wallace et al., 2009). These studies found strong correlations between athletes- and coaches-perceived training intensity $(r=.75-.84)$, similar to those obtained in the present study. We suggest that these results could be related to more hours of tactical and technical training compared with purely physical sessions (Figure 3), since tactical and technical sessions are closer to the actions contained in soccer matches.

A study conducted by Delattre, Garcin, Mille-Hamard, and Billat (2006) showed that cyclists tend to overestimate the training load proposed by the independent technician. However, our data are consistent with studies conducted with volleyball players (Andrade Nogueira et al., 2014), which showed that regardless of the tactical position taken by the players, all positions agreed in relation to RPE between coaches and players. Unlike our findings, elite young (under 17 and under 19 years of age) soccer players (Brink et al., 2014) perceived their training load as being more difficult than intended by the coach (Brink et al., 2014), although the intensity of the sessions was not equivalent. In this respect, we can assume that the experience of adult professional players to identify intended training loads is evident (Foster, Heimann, et al., 2001). This fact is important because there seems to be a relationship between inefficient training and lack of consistency between what is prescribed and what is performed by athletes (Foster, Florhaug, et al., 2001). Through our findings, we can understand that the coaching staff provided sufficient and structured periodization, since athletes were able to perceive the objective proposed by the technical committee.

Based on the results shown in Figure 4, no significant differences were found between the training loads for physical, technical, or tactical training. The analysis of the training load perceived by players for the different types of training suggest that professional soccer players perform similarly to that intended by coaching staff, in different requirements (intensities) that represent sessions within a periodization program. Other studies (Andrade Nogueira et al., 2014; Brink et al., 2014; Wallace et al., 2009) supplement their analysis by categorizing training intensities into intensity categories such as: RPE $<3$ or $<13$, easy training; RPE 3-5 or 13-4, moderate training; and RPE $>5$ or $>14$, hard training. 
However, it is noteworthy that the choice of session type, as well as the duration, was defined by the technical coach. Therefore, we decided to classify the training according to the understanding of the coaching staff and not in accordance with an intensity category based on RPE. The technical coach determined that the training would be technical, physical, or tactical. For this reason, in an attempt to reflect the reality presented in sports, in this case, professional soccer (in Brazil), we maintained this approach.

\section{Limitations and Conclusion}

An interesting fact to be addressed is that despite having different tactical positions involved in soccer (functions of the players), the training for the soccer players in the present study was carried out for the group in a standardized way (except for the goalkeepers - data not included in this research), regardless of the different demands presented during the games (Bangsbo, Mohr, \& Krustrup, 2006). For this purpose, as highlighted by Nogueira et al. (2014), when athletes perform the same training, it is essential for the coach to identify different values of RPE (Andrade Nogueira et al., 2014). This brings us to the limitations of our study; we did not separate the tactical positions and did not evaluate any physiological variables. Another limitation may be related to considering only the duration of the training sessions and not their content, assuming that all the morning or afternoon training sessions had a similar mean workload. However, the S-RPE method requires only two variables for assessment. We suggest future studies use measures to quantify internal (e.g., heart rate) or external (i.e., movement analysis) load. In addition, we also suggest that future studies may help to answer the gaps in the literature regarding the compliance of internal training load perceived by professional players, associated with physiological patterns and performance (i.e., total distance traveled and number of efforts at high intensity), with the intention proposed by the technician. It is important to investigate the differences between the RPE added to the physiological variables to determine if athletes are interpreting the scale correctly (Andrade Nogueira et al., 2014).

To our knowledge, the present study is the first to examine the level of session RPE correlation between professional coaches and soccer players in the adult category. Our findings reinforce the idea of planned periodization, with constant concern in controlling the training load and its importance to avoid overreaching and overtraining in high-performance athletes training. With regard to the training load through the S-RPE method, coaches should consider the answers presented in previous sessions, since this factor can influence the perception of subsequent training.

In conclusion, in soccer, despite the different tactical positions, with characteristics peculiar to each function of the game, there were no statistical differences in load perceptions of the players in the different types of training offered. 
We can assume that, although it is desirable to use technological tools for load training control (i.e., heart rate monitors, fitness trackers, GPS, and others), the session RPE is a simple and plausible method to be employed in professional soccer teams. Based on the characteristics of individuals and methodology of this study, we conclude that the session RPE during the preseason period in professional soccer players was not different between coaches and players.

\section{Declaration of Conflicting Interests}

The author(s) declare no potential conflicts of interest with respect to the research, authorship, and/or publication of this article.

\section{Funding}

The author(s) received no financial support for the research, authorship, and/or publication of this article.

\section{References}

Andrade Nogueira, F. C. d., Nogueira, R. A., Coimbra, D. R., Miloski, B., Freitas, V. H., \& Filho, M. B. (2014). Internal training load: Perception of volleyball coaches and athletes. Revista Brasileira de Cineantropometria \& Desempenho Humano, 16, 638-647.

Bangsbo, J., Mohr, M., \& Krustrup, P. (2006). Physical and metabolic demands of training and match-play in the elite football player. Journal of Sports Sciences, 24, 665-674.

Borin, J. P., de Godoy Dias, R., dos Santos Leite, G., Padovani, C. R. P., \& Padovani, C. R. (2010). Indicadores de desempenho e percepção subjetiva de esforço entre técnico e atletas de voleibol. Brazilian Journal of Biomotricity, 4, 123-130.

Brink, M. S., Frencken, W. G., Jordet, G., \& Lemmink, K. A. (2014). Coaches' and players' perceptions of training dose: Not a perfect match. International Journal of Sports Physiology \& Performance, 9, 497-502.

Buchheit, M., Racinais, S., Bilsborough, J., Bourdon, P. C., Voss, S. C., Hocking, J.,... Coutts, A. J. (2013). Monitoring fitness, fatigue and running performance during a pre-season training camp in elite football players. Journal of Science \& Medicine in Sport, 16, 550-555.

Cohen, J. (1988). Statistical power analysis for the behavioral sciences. Hillsdale, NJ: Lawrence Erlbaum Associate.

Coutts, A. J., Gomes, R. V., Viveiros, L., \& Aoki, M. S. (2010). Monitoring training loads in elite tennis. Brazilian Journal of Kinanthropometry \& Human Performance, 12, 217-220.

Delattre, E., Garcin, M., Mille-Hamard, L., \& Billat, V. (2006). Objective and subjective analysis of the training content in young cyclists. Applied Physiology, Nutrition, \& Metabolism, 31, 118-125.

Foster, C. (1998). Monitoring training in athletes with reference to overtraining syndrome. Medicine \& Science in Sports \& Exercise, 30, 1164-1168. 
Foster, C., Florhaug, J. A., Franklin, J., Gottschall, L., Hrovatin, L. A., Parker, S.,...Dodge, C. (2001). A new approach to monitoring exercise training. The Journal of Strength \& Conditioning Research, 15, 109-115.

Foster, C., Heimann, K., Esten, P., Brice, G., \& Porcari, J. P. (2001). Differences in perceptions of training by coaches and athletes. South African Journal of Sports Medicine, 8, 3-7.

Herman, L., Foster, C., Maher, M., Mikat, R. P., \& Porcari, J. P. (2006). Validity and reliability of the session-RPE method for monitoring exercise training intensity: Original research article. South African Journal of Sports Medicine, 18, 14-15, 17.

Impellizzeri, F. M., Rampinini, E., Coutts, A. J., Sassi, A., \& Marcora, S. M. (2004). Use of RPE-based training load in soccer. Medicine and Science in Sports \& Exercise, 36, 1042-1047.

Impellizzeri, F. M., Rampinini, E., \& Marcora, S. M. (2005). Physiological assessment of aerobic training in soccer. Journal of Sports Sciences, 23, 583-592.

Landis, J. R., \& Koch, G. G. (1977). The measurement of observer agreement for categorical data. Biometrics, 33, 159-174.

Lovell, T. W., Sirotic, A. C., Impellizzeri, F. M., \& Coutts, A. J. (2013). Factors affecting perception of effort (session rating of perceived exertion) during rugby league training. International Journal of Sports Physiology \& Performance, 8, 62-69.

McGuigan, M. R., Al Dayel, A., Tod, D., Foster, C., Newton, R. U., \& Pettigrew, S. (2008). Use of session rating of perceived exertion for monitoring resistance exercise in children who are overweight or obese. Pediatric Exercise Science, 20, 333-341.

Mohr, M., Krustrup, P., \& Bangsbo, J. (2003). Match performance of high-standard soccer players with special reference to development of fatigue. Journal of Sports Sciences, 21, 519-528.

Moreira, A., Freitas, C. G. d., Nakamura, F. Y., \& Aoki, M. S. (2010). Percepção de esforço da sessão e a tolerância ao estresse em jovens atletas de voleibol e basquetebol. Brazilian Journal of Kinanthropometry \& Human Performance, 12, 345-351.

Nakamura, F. Y., Moreira, A., \& Aoki, M. S. (2010). Monitoramento da carga de treinamento: a percepção subjetiva do esforço da sessão é um método confiável? Revista da Educação Física/UEM, 21, 1-11.

Rowntree, D. (1981). Statistics without tears: A primer for non-mathematicians. Harmondsworth, Penguin, London: Scribner Book Company.

Scott, T. J., Black, C. R., Quinn, J., \& Coutts, A. J. (2013). Validity and reliability of the session-RPE method for quantifying training in Australian football: A comparison of the CR10 and CR100 scales. The Journal of Strength \& Conditioning Research, 27, $270-276$.

Scott, B. R., Lockie, R. G., Knight, T. J., Clark, A. C., \& Jonge, A. A. K. J. (2013). A comparison of methods to quantify the in-season training load of professional soccer players. International Journal of Sports Physiology \& Performance, 8, 195-202.

Tessitore, A., Meeusen, R., Cortis, C., \& Capranica, L. (2007). Effects of different recovery interventions on anaerobic performances following preseason soccer training. The Journal of Strength \& Conditioning Research, 21, 745-750.

Viru, A., \& Viru, M. (2000). Nature of training effects. In W. Garrett \& M. Kirkendall (Eds.), Exercise \& Sports Science (pp. 67-95). Philadelphia: Lippincott Williams \& Williams. 
Viveiros, L., Costa, E. C., Moreira, A., Nakamura, F. Y., \& Aoki, M. S. (2011). Monitoramento do treinamento no judô: comparação entre a intensidade da carga planejada pelo técnico e a intensidade percebida pelo atleta. Brazilian Journal of Sports Medicine, 17, 266-269.

Wallace, L. K., Slattery, K. M., \& Coutts, A. J. (2009). The ecological validity and application of the session-RPE method for quantifying training loads in swimming. The Journal of Strength \& Conditioning Research, 23, 33-38.

\section{Author Biographies}

Paulo Eduardo Redkva, PhD student, Post-Graduate Program in Sciences Motricity, UNESP-Univ Estadual Paulista, Rio Claro-SP, and has been conducting research in the area of exercise physiology for 10 years.

Sergio Gregorio da Silva, $\mathrm{PhD}$, is an associate professor of Physical Education Teacher Education at UFPR-Federal University of Paraná, Curitiba-PR.

Mauro Ricetti Paes, PhD student, Post-Graduate Program in Physiology, Federal University of Paraná, Curitiba-PR.

Júlio Wilson dos-Santos, $\mathrm{PhD}$, is an associate professor of Physical Education Teacher Education at UNESP - Univ Estadual Paulista, Rio Claro-SP. 